\title{
Minimally Modified Low Density Lipoprotein Stimulates Monocyte Endothelial Interactions
}

\author{
Judith A. Berliner," Mary C. Territo, ${ }^{\ddagger}$ Alex Sevanian, ${ }^{5}$ Soroush Ramin, ${ }^{*}$ Jeong Ai Kim,* \\ Babak Bamshad," Mark Esterson, ${ }^{*}$ and Alan M. Fogelman" \\ Departments of *Pathology and ${ }^{\ddagger}$ Medicine, University of California School of Medicine, Los Angeles, California 90024-1732; and the \\ Department of Pathology and ${ }^{\S}$ Institute for Toxicology, University of Southern California, Los Angeles, California 90007
}

\begin{abstract}
The effect of minimally modified LDL (MM-LDL) on the ability of large vessel endothelial cells (EC) to interact with monocytes and neutrophils was examined. These LDL preparations, obtained by storage or by mild iron oxidation, were indistinguishable from native LDL to the LDL receptor and were not recognized by the scavenger receptor. Treatment of EC with as little as $0.12 \mu \mathrm{g} / \mathrm{ml}$ MM-LDL caused a significant increase in the production of chemotactic factor for monocytes (sevenfold) and increased monocyte binding (three- to fivefold). Monocyte binding was maximal after $4 \mathrm{~h}$ of EC exposure to MM-LDL, persisted for $48 \mathrm{~h}$, and was inhibited by cycloheximide. In contrast, neutrophil binding was not increased after 1-24 h of exposure. Activity in the MM-LDL preparations was found primarily in the polar lipid fraction. MM-LDL was toxic for EC from one rabbit but not toxic for the cells from another rabbit or any human umbilical vein $\mathrm{EC}$. The resistant cells became sensitive when incubated with lipoprotein in the presence of cycloheximide, whereas the sensitive strain became resistant when preincubated with sublethal concentrations of MM-LDL. We conclude that exposure of EC to sublethal levels of MM-LDL enhances monocyte endothelial interactions and induces resistance to the toxic effects of MM-LDL. (J. Clin. Invest. 1990. 85:1260-1266.) oxidized • lipoprotein $\bullet$ activation $\bullet$ binding $\bullet$ chemotaxis
\end{abstract}

\section{Introduction}

Oxidized lipoproteins have been found to be present in atherosclerotic plaques $(1,2)$, and products of oxidation have been seen in early and late lesions in Watanabe heritable hyperlipidemic (WHHL) rabbits $(3,4)$. These lipoproteins have also been reported to be present in the blood of humans and experimental animals at risk to develop lesions (5-7). There is increasing evidence that oxidized lipoproteins may play an important role in atherogenesis, since development of lesions can be reduced by treatment of WHHL rabbits with potent antioxidants, probucol, or butylated hydroxytoluene $(8,9)$.

Among the earliest events in atherogenesis is the binding of monocytes to the endothelium and their entry into the vessel

Address correspondence to Dr. Judith Berliner, Department of Pathology, 13-188 Center for the Health Sciences, University of California, Los Angeles, CA 90024-1732.

Received for publication 5 July 1989 and in revised form 29 November 1989.

\section{J. Clin. Invest.}

(c) The American Society for Clinical Investigation, Inc. 0021-9738/90/04/1260/07 \$2.00

Volume 85, April 1990, 1260-1266 wall $(10,11)$. Increased interaction of monocytes with the endothelium is seen in areas of predilection in cholesterol-fed animals, and it is in these areas that lesions first develop (10). Previous studies have shown that LDL tends to accumulate in these areas and that the LDL residence time is increased (12); this increase might allow for cellular oxidation of the LDL. Other studies have shown that LDL can be oxidized by endothelium $(13,14)$, smooth muscle cells $(13,15)$, and macrophages in culture (16). The mechanism by which LDL is oxidized in the vessel wall in vivo is not known, but it is clear that it must occur in the presence of at least some plasma transferrin, ceruloplasmin, and vitamin E. Several mechanisms have been suggested that would be facilitated by a long residence time in the vessel wall and involve direct contact of LDL with surrounding cells (17). In early lesions the amount of oxidation would be relatively small since the subendothelial space at this stage is mainly acellular as compared with the fatty streak where highly oxidized LDL has been found $(3,4)$. In the present study we have examined whether treatment of endothelial cells $(E C)^{1}$ in culture with minimally modified LDL (MMLDL; 2-5 nmol thiobarbituric acid-reactive substance (TBARS)/mg cholesterol) increased binding of monocytes and production of monocyte chemotactic factor. The effect on monocyte endothelial interactions was compared with the effect on neutrophil endothelial interactions. In addition, the toxicity of MM-LDL was examined.

\section{Methods}

Cell preparation. Rabbit aortic EC (RAEC) at passages 6-17 and human umbilical vein (HUV) EC at passages 1-4 were used (18). For these studies monocytes were obtained by a modification of the Recalde method (19). In brief, with this method citrated plasma is mixed with plasmagel and red blood cells allowed to sediment. A pellet of leukocytes is obtained by centrifugation at $600 \mathrm{~g}$ for $10 \mathrm{~min}$, and these leukocytes are incubated in a slightly hypertonic solution for $\sim 30 \mathrm{~min}$ at $37^{\circ} \mathrm{C}$. During this time the lymphocytes become more dense, whereas the monocytes do not. The monocytes are separated from lymphocytes using Ficoll-Hypaque. The mononuclear cell band contains $\sim 75 \%$ monocytes and $25 \%$ lymphocytes. It is this preparation that was used directly for the present studies. Although these preparations contained $25 \%$ lymphocytes and we routinely had only $15 \%$ lymphocytes in our preparations of elutriated monocytes, similar results were found with the use of monocytes obtained by elutriation for the response to EC chemotactic factor (19) and for monocyte binding (data not shown). The modified Recalde method has the advantages of being rapid and not involving adherence of monocytes, which may

1. Abbreviations used in this paper: B-VLDL, beta-VLDL; C-epox, cholesterol epoxide; EC, endothelial cells; Fe-ox, iron oxidation; HPF, high power field; HUV, human umbilical veins; MDA-LDL, malondialdehyde-treated LDL; MM-LDL, minimally modified LDL; PC, phosphatidylcholine; RAEC, rabbit aortic endothelial cells; TBARS, thiobarbituric acid-reactive substance. 
cause activation. Neutrophils were obtained by a Ficoll-Hypaque separation followed by a dextran sedimentation (20). The human monocyte cell line THP-1 (ATCC TIB202; American Type Culture Collection, Rockville, MD) was also used as a source of monocyte-like cells.

Lipoprotein preparation and analysis. LDL was isolated by density gradient centrifugation of serum and stored in phosphate-buffered 0.15 $\mathrm{M} \mathrm{NaCl}$ containing $0.01 \%$ EDTA (buffer B). MM-LDL was obtained by storage of $\mathrm{LDL}$ at $4^{\circ} \mathrm{C}$ for 3-6 mo in plastic tubes. Iron-oxidized (Fe-ox) LDL ( $5 \mathrm{nmol}$ TBARS/mg cholesterol) was prepared by previously described methods (21). In several cases stored and freshly isolated LDL from the same individual were compared. Cholesterol- $\alpha$ epoxide (C-epox), prepared as described previously (22), was added to freshly isolated LDL preparations as follows: $20 \mu \mathrm{l} \mathrm{C-}$ epox $(1 \mathrm{mg} / \mathrm{ml}$ in ethanol) was added to $1 \mathrm{mg}$ of LDL in buffer $B$; the mixture was incubated at $37^{\circ} \mathrm{C}$ for $1 \mathrm{~h}$ with occasional gentle mixing. MM-LDL was separated into lipid and aqueous portions using chloroform methanol extraction (23), and neutral lipids were separated using diol extraction columns according to previously described methods (24) (Analytichem International, Inc., Harbor City, CA). The separated lipids were added to the cells as liposomes obtained by extrusion (25). For the neutral lipids exogenous dipalymitoyl phosphatidylcholine (PC), at a ratio of $6 \mathrm{~mol} \mathrm{PC} / \mathrm{mol}$ neutral lipid, was added to facilitate liposome formation.

To separate PC from lyso PC via TLC, an aliquot of the polar lipid was spotted onto a TLC plate and developed in 65:25:4 chloroform:methanol:water solution. The sample lanes were covered with a glass plate and the PC and lyso PC standard spots were identified by iodine vapor and determined to have retention factor values of 0.28 and 0.08 , respectively. Using these retention factor values, lyso PC and PC regions from the samples were scraped into separate test tubes. The samples were extracted off the scraped silica in methanol and dried under nitrogen. The final amounts of lyso PC and PC in MM-LDL and untreated LDL samples were measured by determining the amount of phosphorus in each extract (26). Recoveries were monitored at all steps with $\left[{ }^{3} \mathrm{H}\right] \mathrm{PC}$ and lyso PC.

Adhesion assay. For adhesion studies EC were cultured in 48-well dishes in media containing $5 \%$ calf serum, with or without native LDL, or MM-LDL, and incubated for the stated times at $37^{\circ} \mathrm{C}$. Some cells were placed in medium containing LPS $(1 \mu \mathrm{g} / \mathrm{ml})$ for $4 \mathrm{~h}$. Adhesion assays were carried out as described by Pawlowski et al. (27). The wells, containing EC, were rinsed three times with serum-free medium, and 2 $\times 10^{5}$ monocytes, or neutrophils in Dulbecco's modified Eagles medium containing $1 \%$ heat-inactivated serum, were added to each well. After $1 \mathrm{~h}$ the nonadherent leukocytes were rinsed off and the wells were fixed with $1 \%$ glutaraldehyde. The number of attached leukocytes was counted in each of 20 microscopic fields. In some experiments THP cells rather than monocytes were used. These cells were labeled with $\left[{ }^{3} \mathrm{H}\right]$ thymidine and the number of bound cells was determined by solubilizing cells with $0.4 \mathrm{~N} \mathrm{NaOH}$ and counting in a scintillation counter.

Chemotactic factor production. For studies of chemotactic factor production, EC were placed in medium containing $1 \%$ heat-inactivated fetal bovine serum with or without lipoprotein for $24 \mathrm{~h}$. The medium was then collected and tested for chemotactic activity in a Neuroprobe chamber (Neuroprobe, Bethesda, MD) as described previously (18). Positive controls using the chemotactic peptide FMLP and negative control medium (medium that was not exposed to EC) were run simultaneously with the test samples. Approximately three cells/high power field (HPF) were seen in the negative controls and $\sim 35$ cells/HPF were seen in cells containing the positive controls.

Assays for products of lipid peroxidation. TBARS were measured using methods previously described (28). Hydroperoxides were determined on a lipid extract of the lipoproteins using the method of Asakawa and Matsushita (29). Lipid was extracted with 5 vol of ethyl acetate containing $0.1 \%$ acetic acid, followed by 5 vol of methylene chloride. The organic solvents were pooled and removed by drying under nitrogen and the residue was tested for peroxide. The data are expressed as the nanomole equivalents of iodate. C-epox levels were measured by gas chromatography using a $30-\mathrm{m}$ by $0.53-\mathrm{mm}$ DB-1 column (J \& W Scientific, Folsom, CA) (30). Chromatographic conditions were as follows: the initial column temperature was $180^{\circ} \mathrm{C}$, and the temperature was programmed at $16^{\circ} \mathrm{C} / \mathrm{min}$ to a final temperature of $290^{\circ} \mathrm{C}$; the total run time was $35 \mathrm{~min}$ with a helium flow rate of 10.5 $\mathrm{ml} / \mathrm{min}$; and the detector temperature was $300^{\circ} \mathrm{C}$.

Lipoprotein degradation. MM-LDL, malondialdehyde-treated LDL (MDA-LDL), and freshly isolated LDL were iodinated and cellular degradation was measured after $4 \mathrm{~h}$ as described previously (31). For competition studies $10 \mu \mathrm{g} / \mathrm{ml}$ of labeled MM-LDL was competed with a 20-fold excess of unlabeled LDL, MDA-LDL, or MM-LDL.

Toxicity. Detachment of the EC was determined by incubating confluent monolayers of $\mathrm{EC}$ with various concentrations of lipoprotein in non-serum-containing media (RAEC) or medium containing 5\% serum (HUV) for $24 \mathrm{~h}$. Detached cells were removed by washing, and the protein content of the remaining cells was assayed by the reagent method (Bio-Rad Laboratories, Richmond, CA). In some studies cells were labeled with $\left[{ }^{14} \mathrm{C}\right]$ leucine and the number of TCA-precipitable counts determined. Percent cell detachment was calculated from the content remaining in the wells as follows: $\frac{\text { untreated }- \text { treated }}{\text { untreated }} \times 100 \%$.

\section{Results}

Lipoprotein composition and uptake. The composition of the MM-LDL and its uptake characteristics were examined. By the Western blotting technique, which detected as little as 10 ng of LPS (bacterial LPS from Escherichia coli strain 0111:B4; List Biological Laboratories, Inc., Campbell, CA), no LPS was detectable in $200 \mu \mathrm{g}$ of the oxidized LDL. LPS alone induced significant monocyte binding only at levels of $500 \mathrm{pg} / \mathrm{ml}$ and LPS-LDL at $20 \mu \mathrm{g} / \mathrm{ml}$ LPS (data not shown). MM-LDL in the present studies was active at $0.12 \mu \mathrm{g} / \mathrm{ml}$, which could contain no more than $3 \mathrm{pg} / \mathrm{ml}$ of LPS, so that LPS did not account for our findings. We next compared the levels of TBARS, hydroperoxide, and C-epox in the MM-LDL preparations (obtained by storage) with that found in freshly isolated LDL. MM-LDL preparations had 1.5-2-fold higher levels of TBARS, 1.5-fold higher hydroperoxide, and 4-fold the level of C-epox compared with that of freshly isolated LDL (Fig. 1). The rate of degradation of MM-LDL was comparable to that of LDL, but MDA-LDL degradation was approximately threefold higher (Fig. $2 A$ ). These results suggest that MM-LDL was taken up by the LDL receptor. This suggestion was strengthened by the observation that LDL but not MDA-LDL suppressed uptake of MM-LDL (Fig. 2 B). Cross-competition studies confirmed that MM-LDL inhibited for uptake of LDL but not MDALDL (data not shown).

Chemotaxis. Treatment of RAEC for $24 \mathrm{~h}$ with MM-LDL at $1 \mu \mathrm{g} / \mathrm{ml}$, stimulated chemotactic factor production by EC sevenfold (Fig. 3). Treatment of RAEC with concentrations up to $100 \mu \mathrm{g} / \mathrm{ml} \mathrm{LDL}$ did not increase chemotactic factor production. Medium containing lipoprotein, but not exposed to EC, was not chemotactic. In some studies concentrations as low as $0.05 \mu \mathrm{g} / \mathrm{ml}$ of MM-LDL caused a significant stimulation of chemotactic factor production, and stimulation at higher concentrations was linearly related to the dose of MM-LDL (Fig. 4). The medium from EC treated with MM-LDL had no chemotactic activity for neutrophils (control $3 \pm 2$, MM-LDL $3 \pm 1$ cells/HPF).

Adhesion. A 24-h pretreatment of RAEC with MM-LDL at $5 \mu \mathrm{g} / \mathrm{ml}$ (but not LDL at concentrations up to $100 \mu \mathrm{g} / \mathrm{ml}$ ) induced a threefold increase in the adhesion of monocytes to 


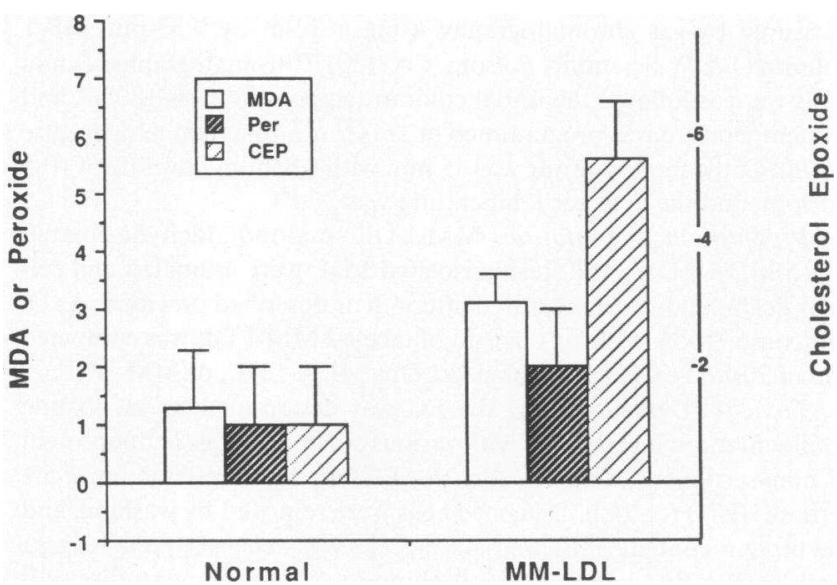

Figure 1. Composition of LDL. Several different freshly isolated (normal) and MM-LDL preparations were examined for $(a)$ the amount of TBARS, given as nanomoles of malondialdehyde equivalents/milligram of cholesterol $(M D A),(b)$ peroxide content (Per) given as nanomoles of iodate equivalent/milligram cholesterol, and (c) C-epox $(C E P)$ in micrograms/milligram cholesterol. Data are mean $\pm S D$. Five different preparations were used for measurement of TBARS and peroxide and three for C-epox.

EC. The magnitude of the increase was similar to that seen after a 4-h pretreatment with LPS $(1 \mathrm{ng} / \mathrm{ml})$ (Fig. 5). Neutrophil adhesion was not stimulated by MM-LDL under the same conditions, but was stimulated by LPS (Fig. 5). In HUV cells, MM-LDL also induced monocyte but not PMN adhesion, while LPS induced adhesion of both cell types (data not shown), indicating that the effect of MM-LDL was not specific to RAEC. A dose-response curve showed that as little as 0.12 $\mu \mathrm{g} / \mathrm{ml}$ of MM-LDL significantly stimulated monocyte adhesion, and the effect was maximal at $1 \mu \mathrm{g} / \mathrm{ml}$ (Fig. 6). After as little as $2 \mathrm{~h}$ of exposure of EC to MM-LDL there was significant stimulation of monocyte binding. Binding was maximal at $4 \mathrm{~h}$ and was sustained at near maximal levels for at least $48 \mathrm{~h}$ (Fig. 7). Neutrophil adhesion was not stimulated by MM-LDL at any time from 1 to $24 \mathrm{~h}$ (data not shown). The increased binding of monocytes was markedly reduced by treating the culture with $1 \mu \mathrm{g} / \mathrm{ml}$ of cycloheximide for $2 \mathrm{~h}$ before the addition of the MM-LDL, suggesting that protein synthesis was necessary for the full induction of monocyte adhesion (Fig. 8).
To obtain further evidence that oxidation of the MM-LDL was responsible for the increased monocyte binding, several preparations of freshly isolated LDL were minimally oxidized using an iron-dependent peroxidizing system $(5 \mathrm{nmol}$ TBARS/mg cholesterol) and their effect on monocyte binding was determined. This MM-LDL prepared by Fe-ox at a concentration of $5-10 \mu \mathrm{g} / \mathrm{ml}$ had an effect comparable to that of stored MM-LDL at $1 \mu \mathrm{g} / \mathrm{ml}$ (untreated, 230 \pm 15 ; MM-LDL, 1,650 \pm 87 ; Fe-ox, 1,963 \pm 120 ).

The experiments in Fig. 9 were performed to determine the active component in MM-LDL inducing adherence. The activity was present in the organic phase of a chloroform methanol extract and was found in the charged lipids of this phase. These polar lipids at $10 \mu \mathrm{g} / \mathrm{ml}$ gave a comparable activity to the whole MM-LDL particle at $3 \mu \mathrm{g} / \mathrm{ml}$. Examination of two preparations of MM-LDL using TLC showed that the polar lipid fraction contained large amounts of lyso PC as compared with freshly isolated LDL (freshly isolated, PC/lyso PC 4.5/1; MM-LDL, 1/1). Lyso PC is a potentially active component that has been shown by others to be chemotactic for monocytes (32).

Since a major oxidation product in MM-LDL was C-epox, the effect on monocyte binding of freshly isolated LDL to which C-epox was added (epox-LDL) was determined. For these studies C-epox was added to LDL, the LDL was dialyzed, and the level of retained C-epox was measured. RAEC were then exposed for $4 \mathrm{~h}$ to $10-1,000 \mathrm{ng} / \mathrm{ml}$ of C-epox incorporated into LDL or $10 \mathrm{ng} / \mathrm{ml}$ of MM-LDL and monocyte binding was compared with that seen with native LDL. Binding was found to be $307 \pm 41,2,157 \pm 141,287 \pm 25,445 \pm 60$, and $1,265 \pm 111 \mathrm{cpm} /$ well for EC exposed to native LDL, MMLDL (10 ng/ml), and C-epox-LDL at 10, 100, and 1,000 $\mathrm{ng} / \mathrm{ml}$, respectively. These results suggest that $\mathrm{C}$-epox alone could not be responsible for the sevenfold increase in binding seen with MM-LDL. However, at 100-fold higher C-epox levels $(1,000 \mathrm{ng} / \mathrm{ml})$ the C-epox-LDL increased binding threefold.

Toxicity. The effect on cell detachment of MM-LDL for two strains of RAEC at passage 11 and cells from six different isolates of HUV at passage 3 were examined (Fig. 10). In nonserum medium or in medium containing 5\% FCS (data not shown), MM-LDL was toxic for one strain of RAEC with an $\mathrm{LD}_{50}$ of $20 \mu \mathrm{g} / \mathrm{ml}$, but was nontoxic for another strain of RAEC and was nontoxic for all six isolates of HUV at 120
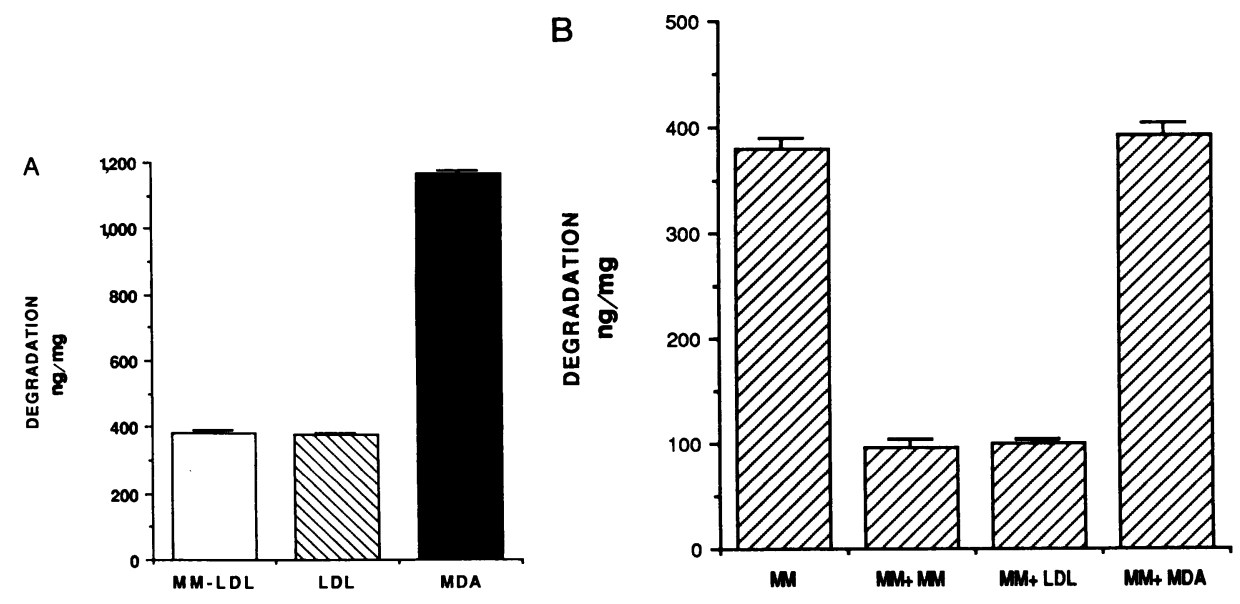

Figure 2. A, Uptake and degradation of MM-LDL. $10 \mu \mathrm{g} / \mathrm{ml}$ of ${ }^{125}$ I-labeled normal LDL, MM-LDL, or MDA-LDL were added to confluent cultures of RAEC $\left(3 \times 10^{5}\right.$ cells $\left./ \mathrm{cm}^{2}\right)$ and uptake and degradation measured over a 4-h period. Two different preparations of each type of LDL were used and values represent mean $\pm \mathrm{SD}$ of quadruplicate determinations. $B$, Competition studies. The ability of a 20 -fold excess of LDL, MM-LDL, and MDA-LDL to suppress degradation of ${ }^{125}$ I-MM-LDL was determined. Values represent mean \pm SD of quadruplicate determinations. 


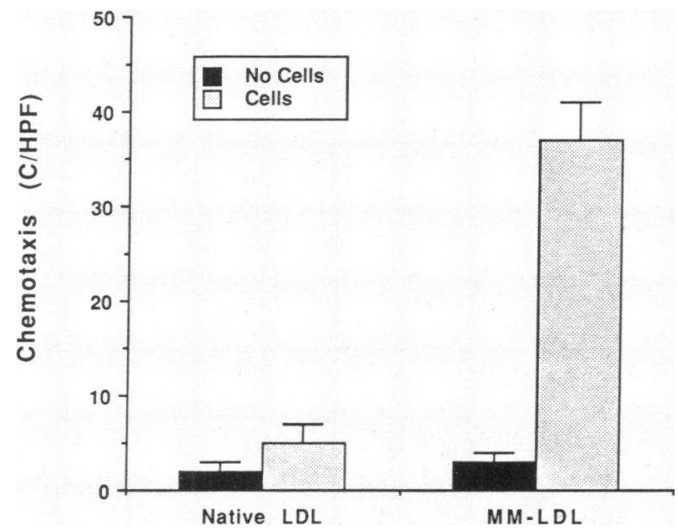

Figure 3. Effect of MM-LDL on chemotactic factor production. Confluent RAEC were treated for $24 \mathrm{~h}$ with $100 \mu \mathrm{g} / \mathrm{ml}$ native LDL or $1 \mu \mathrm{g} / \mathrm{ml} \mathrm{MM-LDL} \mathrm{in} \mathrm{medium} \mathrm{containing} 1 \%$ heat-inactivated fetal bovine serum. The medium was then tested for chemotactic activity on human monocytes. Data are expressed as cells/HPF $(C /$ $H P F$ ) and represent the mean $\pm \mathrm{SD} ; n=6$. No cells, medium from incubations with lipoproteins but without EC. Cells, incubations containing lipoproteins and EC.

$\mu \mathrm{g} / \mathrm{ml}$ in medium containing $5 \%$ FCS. For all the studies on lipoprotein uptake, chemotaxis, and adhesion reported above the resistant strain of RAEC or the sensitive strain exposed to MM-LDL at a concentration 10-fold below toxic levels was used. During our studies we noted that sensitive cells could be made resistant to the toxic effects of MM-LDL by preexposure to a sublethal concentration of MM-LDL. The sensitive cells that were exposed to $4 \mu \mathrm{g} / \mathrm{ml}$ of MM-LDL for $48 \mathrm{~h}$ and then to $40 \mu \mathrm{g} / \mathrm{ml}$ of MM-LDL for $24 \mathrm{~h}$ proved to be resistant to the higher concentration after preexposure to the lower sublethal concentration (Fig. 11). In addition, resistant cells were found to be sensitive to the toxic effects of MM-LDL when incubated in the presence of cycloheximide (Fig. 11) (cycloheximide

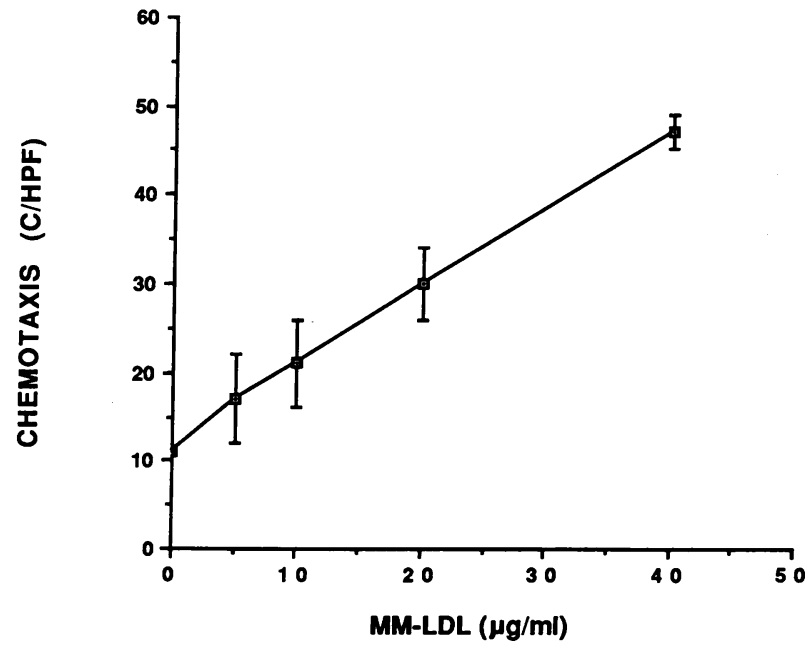

Figure 4. Dose-response curve of the effect of MM-LDL on chemotactic factor production. These studies were performed as for Fig. 3 except that different concentrations of MM-LDL were used. Values represent the mean $\pm \operatorname{SD}(n=4)$. The zero value represents the activity produced by untreated cells. Data are expressed as cells/HPF $(C /$ $H P F)$.
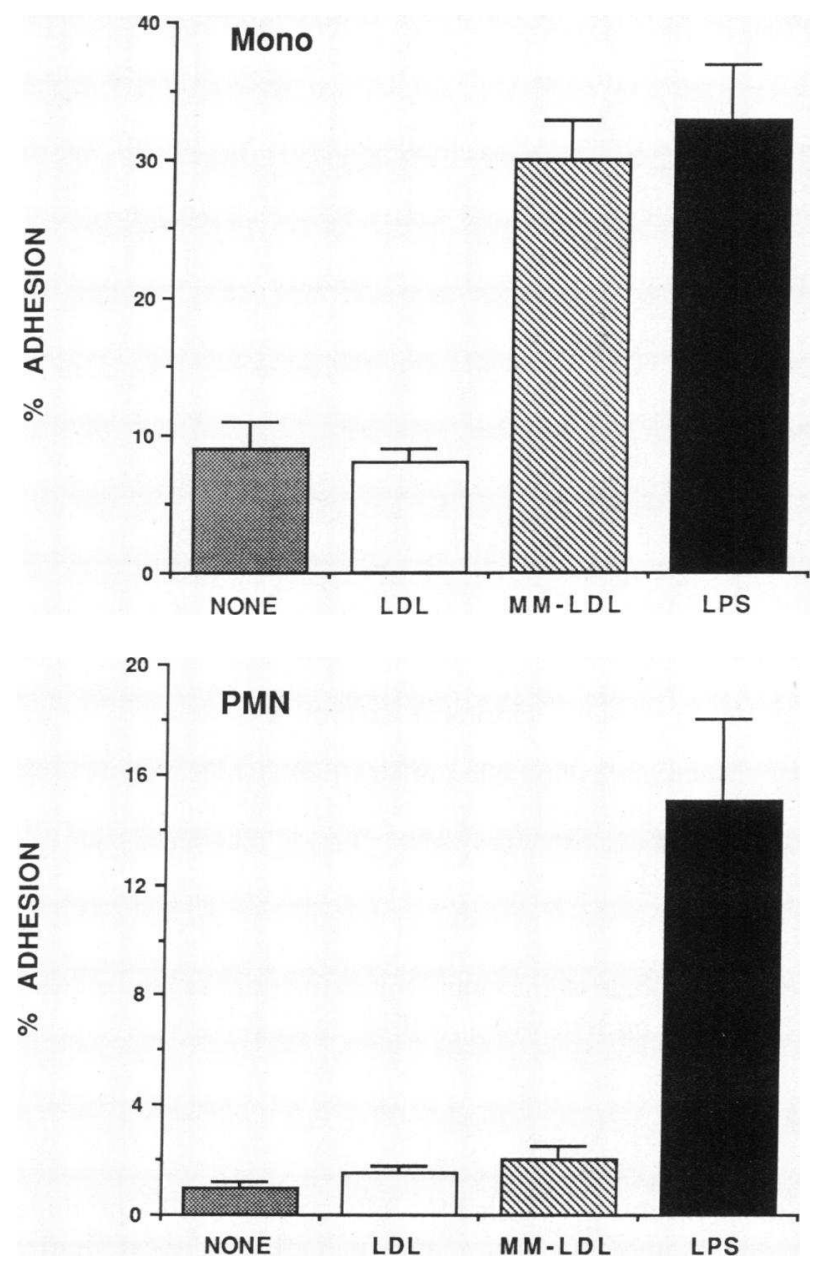

Figure 5. Effect of LPS and lipoprotein on monocyte (top) and neutrophil (bottom) adhesion. RAEC were either (a) untreated (none), (b) treated for $24 \mathrm{~h}$ with native LDL $(100 \mu \mathrm{g} / \mathrm{ml})$ or MM-LDL $(5$ $\mu \mathrm{g} / \mathrm{ml})$, or $(c)$ treated with bacterial LPS $(1 \mathrm{ng} / \mathrm{ml})$ for $4 \mathrm{~h}$. All additions were made in medium containing $5 \%$ serum. After treatment cells were washed with serum-free medium and then monocytes or neutrophils were added to each well for $1 \mathrm{~h}$. Nonadherent cells were washed away and adherent cells visually counted. The data are expressed as the percent of monocytes or neutrophils that adhered to the EC. Values represent mean $\pm \operatorname{SD}(n=6)$.

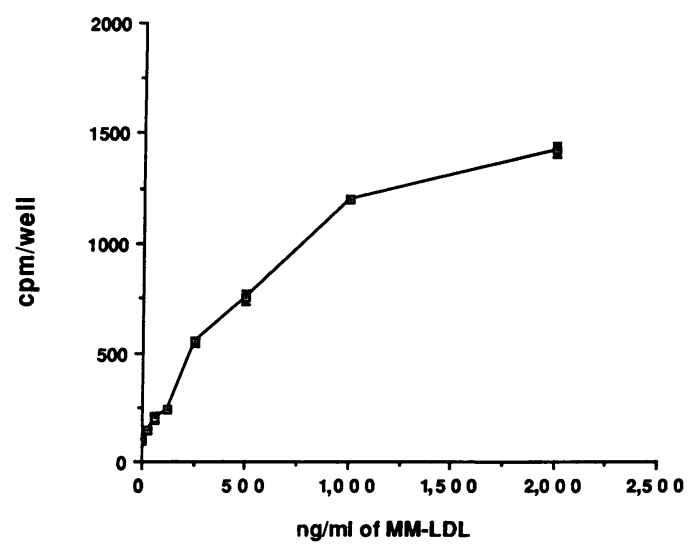

Figure 6. Dose-response curve for the effect of MM-LDL. RAEC were treated for $24 \mathrm{~h}$ with the indicated concentrations of MM-LDL and monocyte adhesion was measured as counts/minute per well. $n$ $=4$. Values are mean $\pm S D$. 


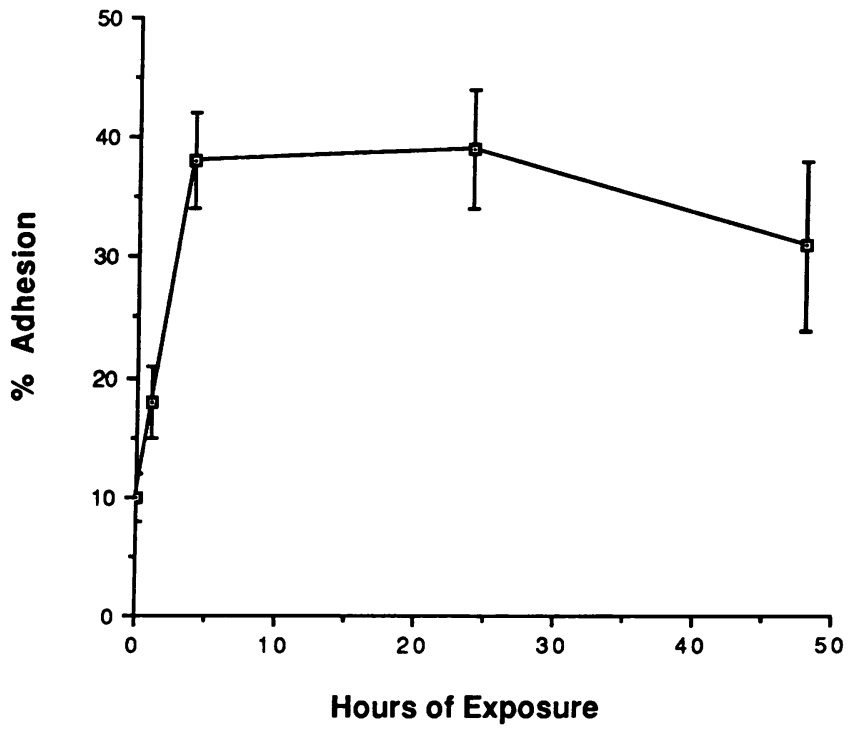

Figure 7. Time course of the effect of MM-LDL. RAEC were treated for the indicated times with $5 \mu \mathrm{g} / \mathrm{ml} \mathrm{MM}-\mathrm{LDL}$ and binding of monocytes was measured as described in Fig. 5. Values represent mean $\pm \mathrm{SD} ; n=4$.

alone was not toxic to the cells), suggesting that resistance was conferred by a protein with a half-life $<24 \mathrm{~h}$.

\section{Discussion}

The mechanisms by which MM-LDL causes EC to produce increased chemotactic factor and increased monocyte adhesion are not yet defined. The fact that increased adhesion can occur as early as $1 \mathrm{~h}$ after treating the cells is significant. This is similar to the time required for the effects of LPS and IL-1 on neutrophil and monocyte adhesion where synthesis of a new endothelial surface protein was required $(33,34)$. The fact that cycloheximide blocked the increase in monocyte binding suggests that MM-LDL may also induce the synthesis of a monocyte binding protein. Unlike IL-1 and LPS, however, the effect of MM-LDL was maintained for at least $48 \mathrm{~h}$, and was specific for monocytes not neutrophils, suggesting that an endothelial protein other than ELAM-1 may be involved.

The polar fraction and hence a phospholipid-associated component of the MM-LDL appears to be most active in inducing monocyte binding, although some effects of C-epox at a high concentration were also seen. Peroxidation of phospholipids in oxidized LDL has previously been observed both in vivo and in vitro $(4,35)$. Cholesterol oxidation readily takes place in phospholipid-rich preparations (23). Moreover, cholesterol oxides are reported to be elevated in the serum of hypercholesterolemic patients to a level of $5 \mu \mathrm{g} / \mathrm{mg} \mathrm{LDL}$ cholesterol (36), a level comparable to that in MM-LDL. Exposure of EC to these LDL may play a role in monocyte binding in such patients since high levels of LDL are present in the plasma. Thus, our results and previous studies suggest that both oxidation products of phospholipids at low levels and cholesterol at higher levels are important in monocyte endothelial interactions.

The cause of the increased monocyte entry into the vessel wall after only a short time of cholesterol feeding in experimental animals or in the early fatty streak in humans is an important issue because this entry starts a chain of events that leads to the formation of the atherosclerotic plaque. We have previously shown that treatment of EC with $50 \mu \mathrm{g} / \mathrm{ml}$ of beta (B)-VLDL or MDA-LDL caused an increase in the production of a monocyte chemotactic factor (18). We (37) as well as others (38) have shown that treatment with B-VLDL increases monocyte adhesion. These studies demonstrated that uptake of an abnormal lipoprotein by EC could increase monocyte EC interactions. However, B-VLDL is present at low levels, if at all, in many humans who develop atherosclerotic plaques, and MDA-LDL may not be produced in the vessel wall until after monocyte influx (3). Therefore, it is significant that in the present study MM-LDL, a molecule that is so minimally modified that it is indistinguishable from native LDL by the LDL receptor, can also cause increased monocyte endothelial interactions at concentrations as low as $0.12 \mu \mathrm{g} / \mathrm{ml}$. Studies by Fox et al. (39) have shown that such minimally oxidized LDL can also inhibit platelet-derived growth factor production. The level of oxidized LDL in the vessel wall would be expected to increase in proportion to plasma LDL levels, but it is likely that other factors are also important in determining the extent

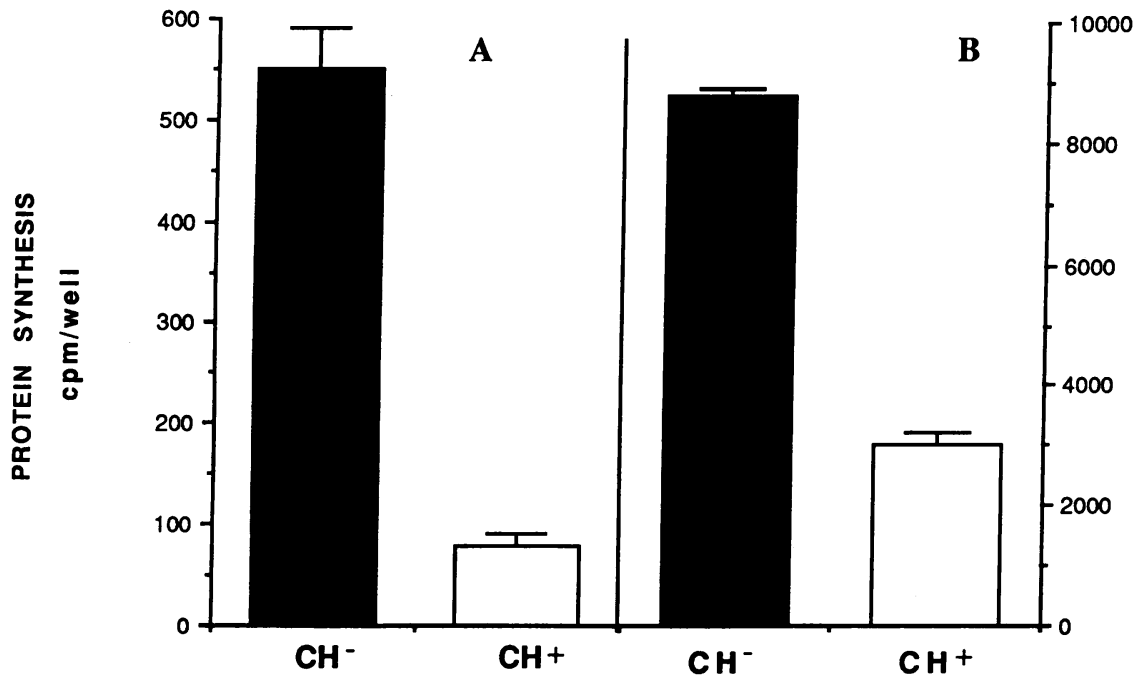

Figure 8. Effect of cycloheximide on the induction of adhesion by MM-LDL. Cells were incubated for $2 \mathrm{~h}$ with $\left(\mathrm{CH}^{+}\right)$or without $\left(\mathrm{CH}^{-}\right)$ cycloheximide $(1 \mu \mathrm{g} / \mathrm{ml})$, then $\mathrm{MM}$ LDL $(1 \mu \mathrm{g} / \mathrm{ml})$ was added to the incubation medium for $4 \mathrm{~h}$ (without removing cycloheximide). The cells were washed and then protein synthesis (uptake of $\left[{ }^{3} \mathrm{H}\right]$ phenylalanine into TCA-precipitable protein) $(A)$ and monocyte binding $(B)$ were determined. Values represent mean $\pm \mathrm{SD} ; n=4$. 


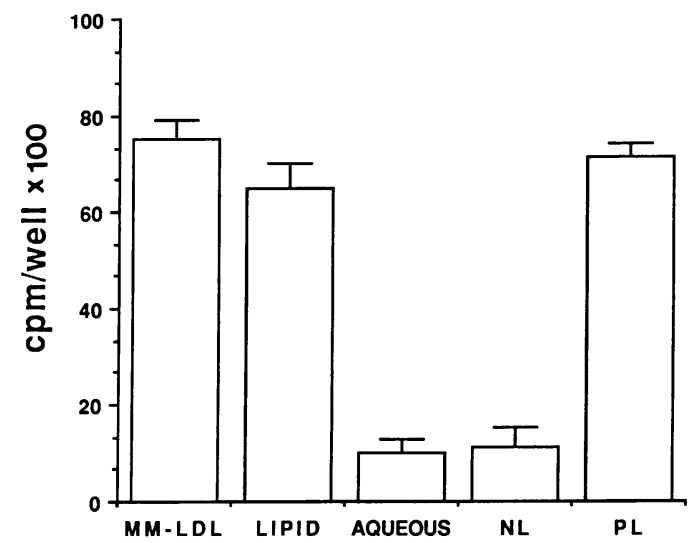

Figure 9. Effect of components of MM-LDL on monocyte binding. MM-LDL was extracted with chloroform methanol and the aqueous and lipid portions were tested. The lipid portion was suspended in methanol and tested at $\sim 10 \mu \mathrm{g} / \mathrm{ml}$, as was the aqueous component. The lipid component was further fractionated into neutral $(N L)$ and charged $(P L)$ lipids. These were incorporated into liposomes and tested at $4 \mu \mathrm{g} / \mathrm{ml}$. The effects on monocyte binding, measured after 4 $\mathrm{h}$, were compared with those on cells treated with unextracted MMLDL $(2 \mu \mathrm{g} / \mathrm{ml})$. Values represent mean counts/minute per well \pm SD: $n=4$.

of LDL oxidation and the reaction of individual cells to MMLDL as seen in the present studies on MM-LDL toxicity.

Others have reported that minimally oxidized LDL at $250-500 \mu \mathrm{g} / \mathrm{ml}$ is toxic for dividing fibroblasts (21). In this study MM-LDL was toxic for one strain of RAEC but not for another strain. In preliminary studies, similar observations of variable sensitivity have been seen in cultures of human aortic EC from different individuals (data not shown). In exploring the basis of resistance we have followed a protocol used by Harlan et al. (40) to test whether LPS resistance in HUV cells might be protein mediated. These investigators found that

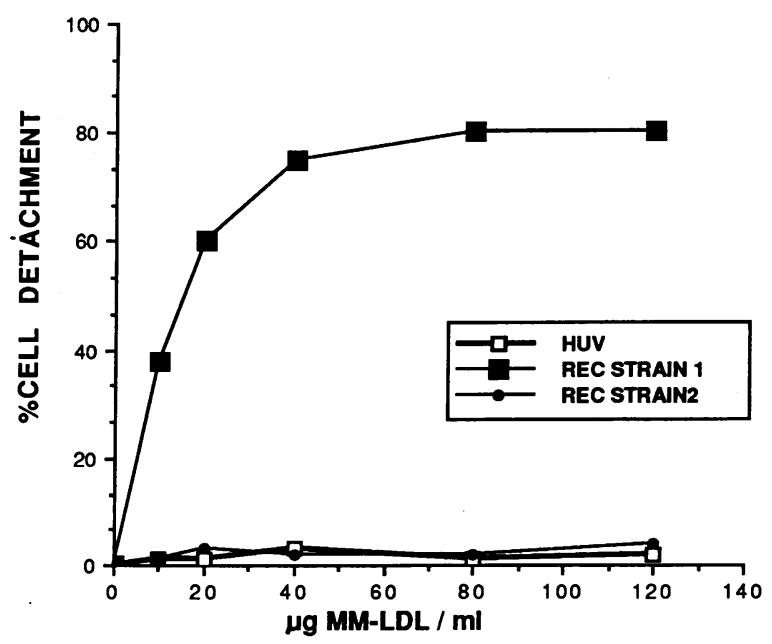

Figure 10. Toxicity of MM-LDL. Confluent, essentially nondividing cultures of two different strains of rabbit aortic EC $(R E C)$ or six isolates of HUV EC ( $H U V$ ) were treated for $24 \mathrm{~h}$ with the indicated concentrations of lipoprotein in serum-free medium. Detached cells were washed away, the remaining attached cells were solubilized with $0.4 \mathrm{~N} \mathrm{NaOH}$, and the protein content was measured using Bio-Rad assay reagent to determine percent cell detachment.

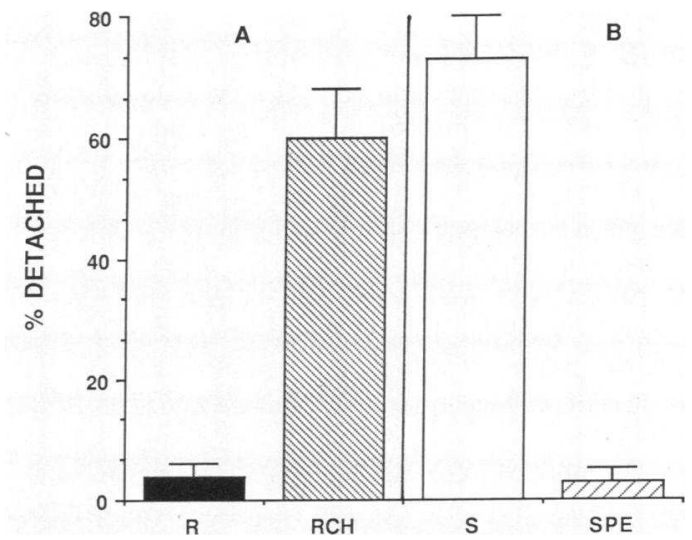

Figure 11. Modulation of toxicity of MM-LDL. A, Resistant cells (strain 2, Fig. 10) were incubated with $40 \mu \mathrm{g} / \mathrm{ml} \mathrm{MM-LDL} \mathrm{for} 24 \mathrm{~h}$ in the absence $(R)$ or presence $(R C H)$ of $1 \mu \mathrm{g} / \mathrm{ml}$ cyclohexamide. $B$, Rabbit cells from strain 1 (Fig. 10), the sensitive strain, either untreated $(S)$ or exposed for $2 \mathrm{~d}$ to $4 \mu \mathrm{g} / \mathrm{ml}$ of MM-LDL (SPE), were exposed for $24 \mathrm{~h}$ to $40 \mu \mathrm{g} / \mathrm{ml}$ of MM-LDL and cell detachment was determined.

preincubation of the HUV with cycloheximide made them sensitive to an otherwise ineffective concentration of LPS. A similar loss of resistance to the toxic effects of MM-LDL in the presence of cycloheximide was seen in the present studies, suggesting the presence of a protective protein. Studies in which sensitive cells were made resistant by preexposure to sublethal levels of MM-LDL suggest that an inducible molecule is involved in resistance.

We propose that at an early stage before fatty streak formation, MM-LDL may be active in stimulating EC to recruit monocytes. Cells from different individuals may respond differently to this agent. Once the fatty streak has been established, with large numbers of macrophages and possibly smooth muscle cells present, there is a high potential for greater LDL modification such as malondialdehyde formation. It is at this stage that the highly modified lipoproteins studied by others $(41,15)$, along with the chemotactic factors produced by smooth muscle cells and macrophages (42-44), may play a major role in sustaining the monocyte migration into the vessel wall.

\section{Acknowledgments}

The authors would like to thank Drs. Margaret Haberland and Mahamed Navab for many helpful discussions, Dr. Paul Di Corleto and Dr. Guy Chisholm for help with the iron oxidation methods, Laura Almada for excellent technical assistance with the cell studies, and Laurine McLeod for essential help with the lipid studies.

The research was supported by National Institutes of Health grants HL-30568, RR-865, and ESO-3466, and the Laubisch Fund.

\section{References}

1. Morton, R. E., G. A. West, and H. F. Hoff. 1986. A low density lipoprotein sized particle isolated from human atherosclerotic lesions is internalized by macrophages via a non-scavenger receptor mechanism. J. Lipid Res. 27:1124-1134.

2. Hoff, H. F., and J. W. Gaubatz. 1982. Isolation, purification and characterization of a lipoprotein containing Apo B from the human aorta. Arteriosclerosis. 42:273-297.

3. Haberland, M. E., D. Fong, and L. Cheng. 1988. Malondialde- 
hyde altered protein occurs in atheroma of WHHL rabbits. Science (Wash. DC). 241:215-218.

4. Palinski, W., M. E. Rosenfeld, S. Yla-Herttuala, G. C. Gurtner, S. S. Socher, S. W. Butler, S. Parthasarathy, T. E. Carew, D. Steinberg, and J. L. Witztum. 1989. LDL undergoes oxidative modification in vivo. Proc. Natl. Acad. Sci. USA. 86:1372-1380.

5. Nishigaki, I., M. Hagihara, H. T. Tsunekawa, M. Maseki, and K. Yagi. 1981. Lipid peroxide levels of serum lipoprotein fractions of diabetic patients. Biochem. Med. 25:373-378.

6. Higuchi, Y. 1982. Lipid peroxides and tocopherol in rat streptozotocin-induced diabetes mellitus. Acta Med. Okayama. 3:165-175.

7. Chisholm, G. M., and D. W. Morel. 1988. Lipoprotein oxidation and cytotoxicity: effect of probucol on streptozotocin-treated rats. $\mathrm{Am}$. J. Cardiol. 62:20B-26B.

8. Kita, T., Y. Nagano, M. Yokode, K. Ishii, N. Kume, A. Ooshuma, H. Yoshida, and C. Kawai. 1987. Probucol prevents the progression of atherosclerosis in WHHL rabbit. Proc. Natl. Acad. Sci. USA. 84:5928-5931.

9. Carew, T. E., D. C. Schwenke, and D. Steinberg. 1987. Antiatherogenic effect of probucol unrelated to the hypocholesterolemic effect: evidence that antioxidants in vivo can selectively inhibit LDL degradation in macrophage rich fatty streaks and slow progression of atherosclerosis in the WHHL rabbit. Proc. Natl. Acad. Sci. USA. 87:7725-7729.

10. Gerrity, R. G., H. K. Naito, M. Richardson, and C. J. Schwartz. 1979. Dietary induced atherogenesis in swine. Am. J. Pathol. 95:775785.

11. Faggiotto, A., R. Ross, and L. Harker. 1984. Studies of hypercholesterolemia in the non-human primate. Arteriosclerosis. 4:323340.

12. Schwenke, D. C., and T. E. Carew. 1987. Determination of the LDL degradation rate, content and residence time in lesioned and nonlesioned aorta. Circulation. 76(Suppl IV):313.

13. Morel, D. W., P. E. DiCorleto, and G. M. Chisolm. 1984. Endothelial and smooth muscle cells after low density lipoprotein in vitro by free radical oxidation. Arteriosclerosis. 4:357-364.

14. Steinbrecher, U. S., S. Parthasarathy, D. S. Leake, J. L. Witztum, and D. Steinberg. 1984. Modification of low density lipoprotein by endothelial cells involves lipid peroxidation and degradation of low density lipoprotein phospholipids. Proc. Natl. Acad. Sci. USA. 81:3883-3887.

15. Heinecke, J. W., H. Rosen, and A. Chait. 1984. Iron and copper promote modification of LDL by human arterial smooth muscle cells. J. Clin. Invest. 74:1890-1894.

16. Cathcart, M. K., D. W. Morel, and G. M. Chisolm. 1985. Monocytes and neutrophils oxidize low density lipoprotein making it cytotoxic. J. Leukocyte Biol. 38:341-350.

17. Steinberg, D., S. P. Parthasarathy, T. E. Carew, J. C. Khoo, and J. L. Witzum. 1989. Modifications of LDL that increase its atherogenicity. N. Engl. J. Med. 320:916-924.

18. Berliner, J. A., M. Territo, L. Almada, A. Carter, E. Shafonsky, and A. M. Fogelman. 1986. Monocyte chemotactic factor produced by large vessel endothelial cells in vitro. Arteriosclerosis. 6:254-258.

19. Fogelman, A. M., F. Elahi, K. Sykes, B. J. Van Lenten, M. C. Territo, and J. A. Berliner. 1988. A modification of the Recalde method for the isolation of human monocytes. J. Lipid Res. 29:12431247.

20. Boyum, A. 1968. Isolation of mononuclear cells and granulocytes from human blood. Scand. J. Clin. Lab. Invest. 21:77-89.

21. Kosugi, K., D. W. Morel, P. E. Di Corleto, and G. M. Chisholm. 1987. Toxicity of oxidized LDL to cultured fibroblasts is selective for S phase of the cell cycle. J. Cell Physiol. 130:311-320.

22. Sevanian, A., and L. L. McLeod. 1986. Catalytic properties and inhibition of cholesterol epoxide hydrolase. J. Biol. Chem. 261:54-59.

23. Sevanian, A., and L. L. McLeod. 1987. Cholesterol autooxidation in phospholipid membrane bilayers. Lipids. 22:627-636.

24. Sevanian, A., and E. Kim. 1985. Phospholipase $A_{2}$ dependent release of fatty acids from peroxidized membranes. J. Free Radicals Biol. \& Med. 1:263-271.
25. Hope, M. J., M. B. Bally, G. Webb, and P. R. Cullis. 1985. Production of large unilamellar vesicles by a rapid-extrusion procedure: characterization of size, trapped volume and ability to maintain a membrane potential. Biochim. Biophys. Acta. 812:55-65.

26. Bartlett, G. R. 1959. Phosphorous assay in column chromatography. J. Biol. Chem. 234:466-468.

27. Pawlowski, N. A., E. L. Abraham, S. Pointer, W. A. Scott, and Z. A. Cohen. 1985. Human monocyte-endothelial cell interaction in vitro. Proc. Natl. Acad. Sci. USA. 82:8208-8212.

28. Lee, D. M. 1980. Malondialdehyde formation in stored plasma. Biochem. Biophys. Res. Commun. 95:1663-1672.

29. Asakawa, T., and S. Matsushita. 1980. A colorimetric microdetermination of peroxide values utilizing aluminum chloride as the catalyst. Lipids. 15:965-967.

30. Maerker, G., and S. Unruh. 1986. Cholesterol oxides. I. Isolation and determination of some cholesterol oxidation products. J. Am. Oil Chem. Soc. 63:767-771.

31. Baker, D. P., B. J. Van Lenten, A. M. Fogelman, P. A. Edwards, C. Kean, and J. A: Berliner. 1984. LDL, scavenger and BVLDL receptors on aortic endothelial cells. Arteriosclerosis. 4:248-255.

32. Quinn, M. T., S. Parthasarathy, and D. Steinberg. 1988. Lysophosphatidylcholine: a chemotactic factor for human monocytes and its potential role in atherogenesis. Proc. Natl. Acad. Sci. USA. 85:2805-2809.

33. Pohlman, T. H., K. A. Stanness, P. G. Beatty, H. D. Ochs, and J. M. Harlan. 1986. An endothelial cell surface factor(s) induced in vitro by lipopolysacharide, interleukin 1 , and tumor necrosis factor- $\alpha$ increases neutrophil adherence by a CDW18-dependent mechanism. J. Immunol. 136:4548-4553.

34. Bevilacqua, M. P., J. S. Pober, D. L. Mendrick, R. S. Cotran, and M. A. Gimbrane. 1987. Identification of an inducible endothelialleukocyte adhesion molecule. Proc. Natl. Acad. Sci. USA. 84:92389242.

35. Parthasarathy, S., V. P. Steinbrecher, J. Barrett, J. L. Witzum, and D. Steinberg. 1985. Essential role of phospholipase $A_{2}$ activity in endothelial cell induced modification of LDL. Proc. Natl. Acad. Sci. USA. 82:3000-3004.

36. Gray, M. F., T. D. V. Lawrie, and C. J. W. Brooks. 1971. Isolation and identification of cholesterol $\alpha$-oxide and other minor sterols in human serum. Lipids. 6:836-843.

37. Territo, M. C., J. A. Berliner, L. Almada, R. Ramirez, and A. M. Fogelman. 1989. BVLDL pretreatment of endothelial monolayers increases monocyte but not neutrophil adhesion. Arteriosclerosis. 9:824-828.

38. Endemann, G., A. Pronzcuk, G. Friedman, S. Lindsey, L. Alderson, and K. C. Hayes. 1987. Monocyte adherence to endothelial cells in vitro is increased by BVLDL. Am. J. Pathol. 126:1-6.

39. Fox, P. L., G. M. Chisholm, and P. E. DiCorleto. 1987. Lipoprotein-mediated inhibition of endothelial cell production of PDGF like protein depends on free radical lipid peroxidation. J. Biol. Chem. 262:6046-6054.

40. Harlan, J. M., L. A. Harker, M. A. Reidy, C. M. Gajdusek, S. M. Schwartz, and G. E. Striker. 1983. LPS mediated bovine endothelial injury in vivo. Lab. Invest. 48:269-274.

41. Quinn, M. T., S. Parthasarathy, L. G. Fong, and D. Steinberg. 1987. Oxidatively modified LDL: a potential role in recruitment and retention of monocyte/macrophages during atherogenesis. Proc. Natl. Acad. Sci. USA. 84:2995-2998.

42. Valente, A. J., D. T. Graves, C. E. Vialle-Valentin, R. Delgado, and C. J. Schwartz. 1988. Purification of a monocyte chemotactic factor secreted by non-human primate vascular cells in culture. Biochemistry. 27:4162-4168.

43. Mazzone, T., M. Jensen, and A. Chart. 1983. Human arterial wall cells secrete factors that are chemotactic for monocytes. Proc. Natl. Acad. Sci. USA. 80:5094-5097.

44. Matsushima, K., C. G. Larsen, G. C. DuBois, and J. J. Openheim. 1989. Purification and characterization of a novel monocyte chemotactic and activating factor produced by a human myelomonocytic cell line. J. Exp. Med. 169:1485-1490. 